\title{
GeoGebra Animated Applets for Teaching Cauchy-Euler Differential Equations in Engineering
}

\author{
Jorge Olivares Funes ${ }^{1}$, Maria Rojas ${ }^{2}$ and Elvis Valero Kari ${ }^{3}$ \\ ${ }^{1}$ Department of Mathematics, Universidad de Antofagasta, Antofagasta Chile \\ ${ }^{2}$ Department of Mathematics, Universidad de Antofagasta, Antofagasta Chile \\ ${ }^{3}$ Department of Mathematics, Universidad de Tarapacá, Arica Chile
}

\begin{abstract}
.
Various studies (1) have already shown that the proper use of GeoGebra helps mathematics in understanding and learning them, that is why we will use this software as an important complement to learning differential equations.
\end{abstract}

GeoGebra is becoming increasingly important in the teaching and learning process, especially in engineering math content. We use GeoGebra to create animated applets. corresponding to the Cauchy-Euler differential equations with emphasis on those of the second linear order and their solutions. These applets were designed as support material for the student since it allows them to visualize and understand the algebraic and geometric characteristics of the solutions.

The sliders produced by the applets for mathematical analysis, greatly help in the development of learning the differential equations see (4).

Keywords: animations; applets; differential equations; GeoGebra; teaching-learning

\section{Introduction}

Currently many researchers recommend the use of educational and interactive software as stated by the NCTM (3) which are cited in (2) and tell us that software is an alternative that unites technology with "mathematical tools as an essential resource with the aim of helping students learn, make sense of mathematical ideas, reason mathematically and communicate their mathematical thinking. "

This article is a continuation and extension of the works (4) "Solving non-homogeneous linear differential equations using the coefficients of the indeterminate method and the variation of parameters by means of GeoGebra and (5)", "Linear Homogeneous Linear Differential Equations of Third and Fourth order through GeoGebra Software for Engineering Students "and the teaching project" Design and implementation of didactic applications for teaching-learning differential equations using Geogebra software for engineering students "presented at the 2018 Chilean Physics Symposium in Antofagasta, Chile. 
2nd International Academic Conference on Education, Teaching \& Learning

\section{Cauchy-Euler Differential Equations with GeoGeobra Applets}

In this part, we will introduce some GeoGebra applets where you can see some differential Cauchy -Euler linear second order equations. These applets are freely available on the site https://www.geogebra.org/m/ajazd6ex

\section{Example 1}

Let $x^{2} \frac{d^{2} y}{d x^{3}}+x \frac{d y}{d x}+\mathrm{y}=0$, whose solution in figure 1 of blue color is $c_{1} \cos (\ln (\mathrm{x}))+$ $c_{2} \operatorname{sen}(\ln (\mathrm{x}))$, where $c_{1}$ and $c_{2}$ vary between -5 and 5 .

Figure 1

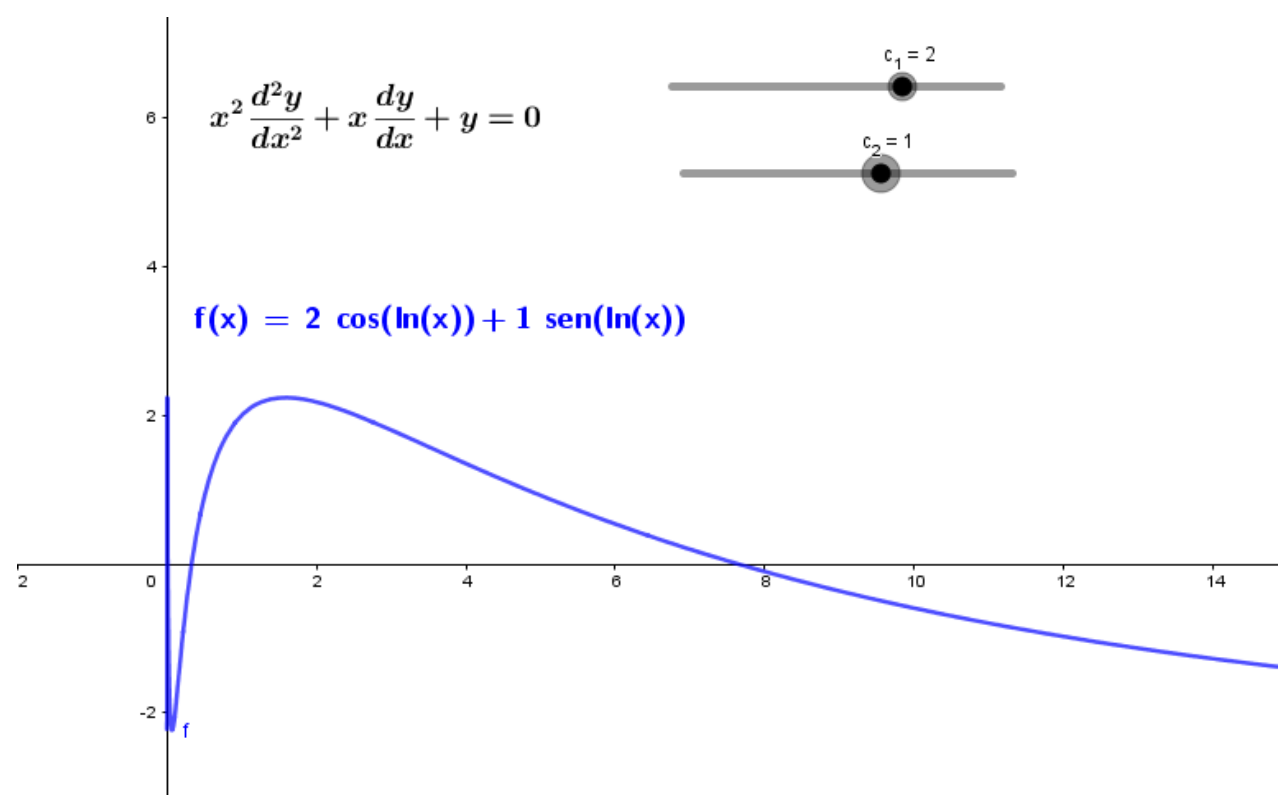

\section{Example 2}

Let $\quad x^{2} \frac{d^{2} y}{d x^{2}}+x \frac{d y}{d x}+4 y=0$, whose solution in figure 2 of blue color is $c_{1} \cos (2 \ln (\mathrm{x}))+c_{2} \operatorname{sen}(2 \ln (\mathrm{x}))$, where $c_{1}$ and $c_{2}$ vary between -5 and 5 .

Figure 2 
2nd International Academic Conference on Education, Teaching \& Learning

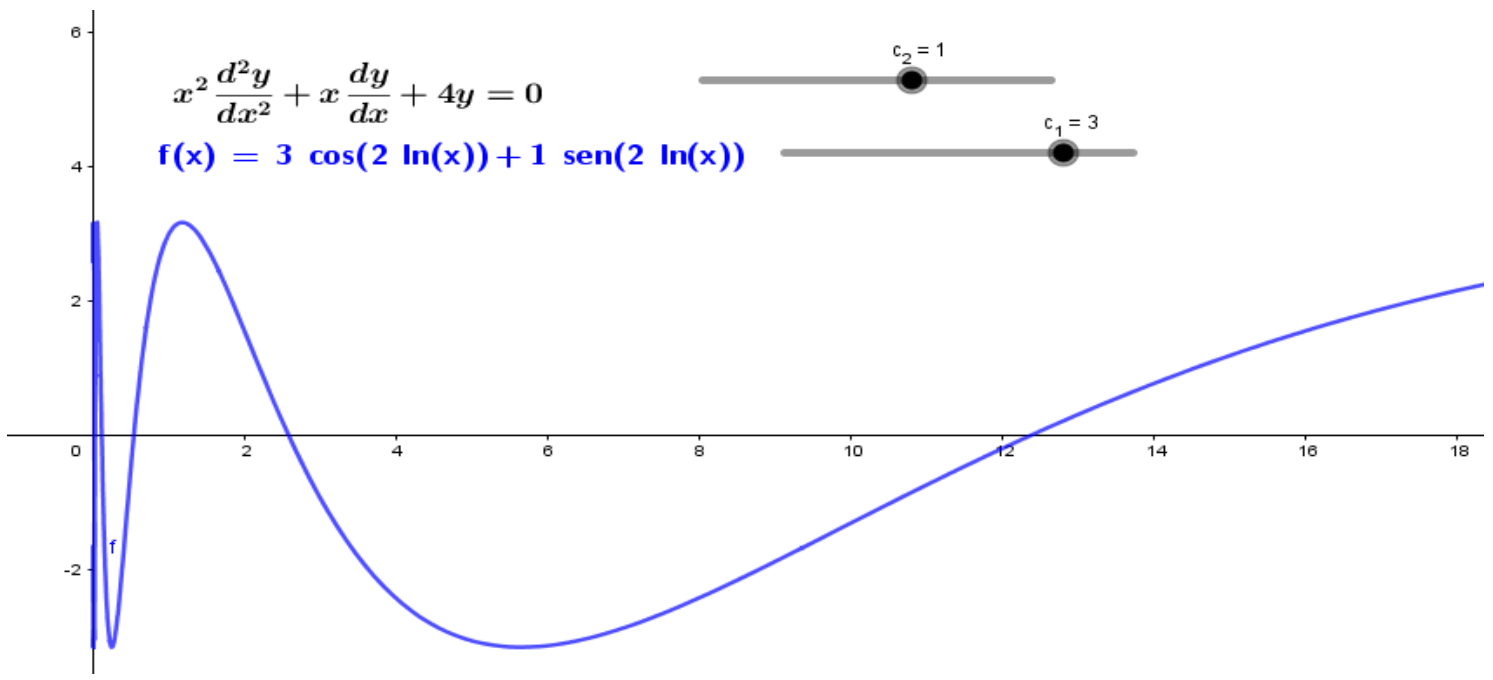

\section{Example 3}

Let $\quad x^{2} \frac{d^{2} y}{d x^{2}}+x \frac{d y}{d x}+9 \mathrm{y}=0$, whose solution in figure 3 of blue color is $c_{1} \cos (3 \ln (\mathrm{x}))+c_{2} \operatorname{sen}(3 \ln (\mathrm{x}))$, where $c_{1}$ and $c_{2}$ vary between -5 and 5 .

Figure 3

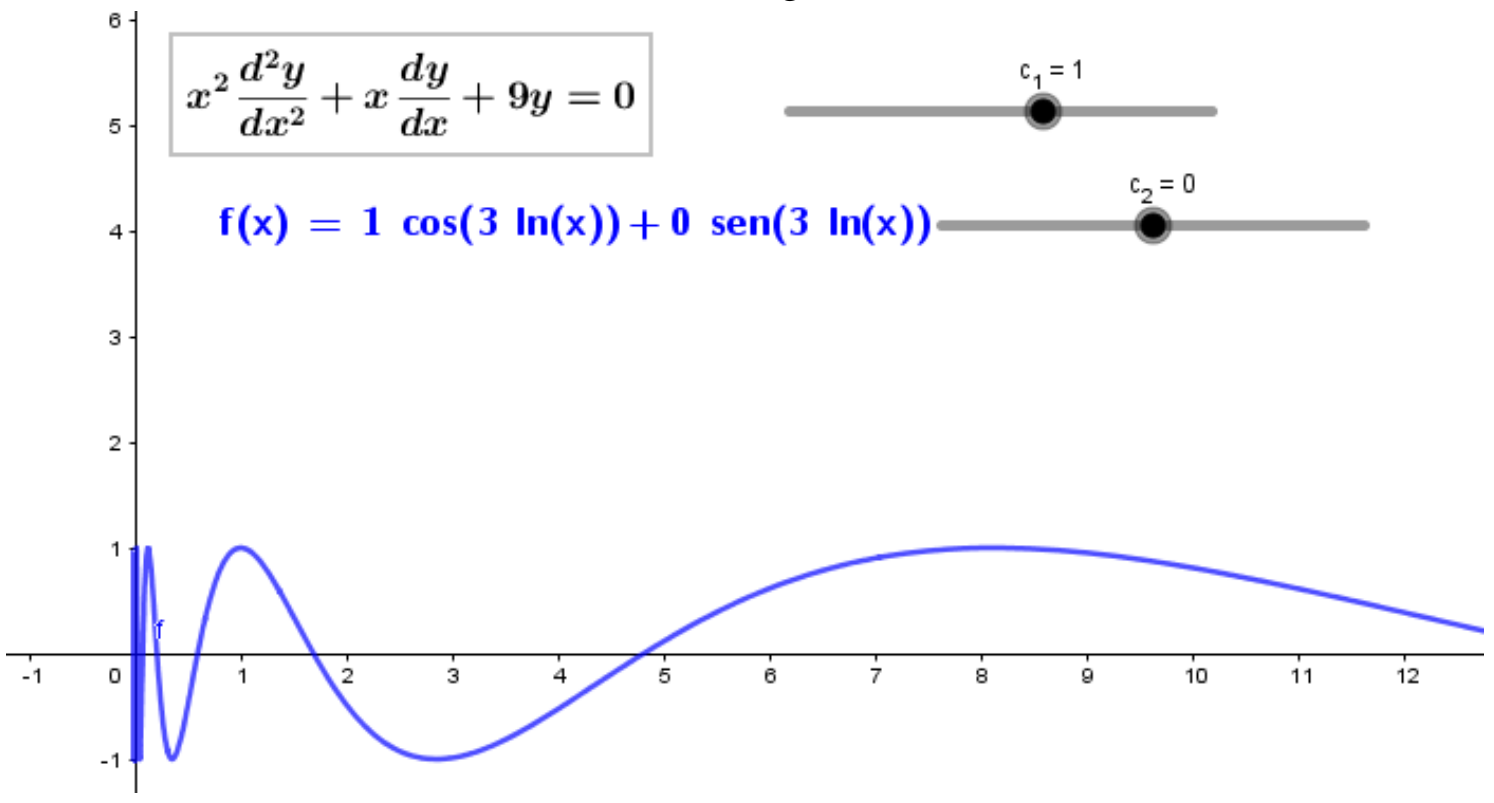

\section{Example 4}

Let $x^{2} \frac{d^{2} y}{d x^{2}}+x \frac{d y}{d x}+25 \mathrm{y}=0$, whose solution in figure 4 of blue color is $c_{1} \cos (5 \ln (\mathrm{x}))+c_{2} \operatorname{sen}(5 \ln (\mathrm{x}))$, where $c_{1}$ and $c_{2}$ vary between -5 and 5 .

Figure 4 


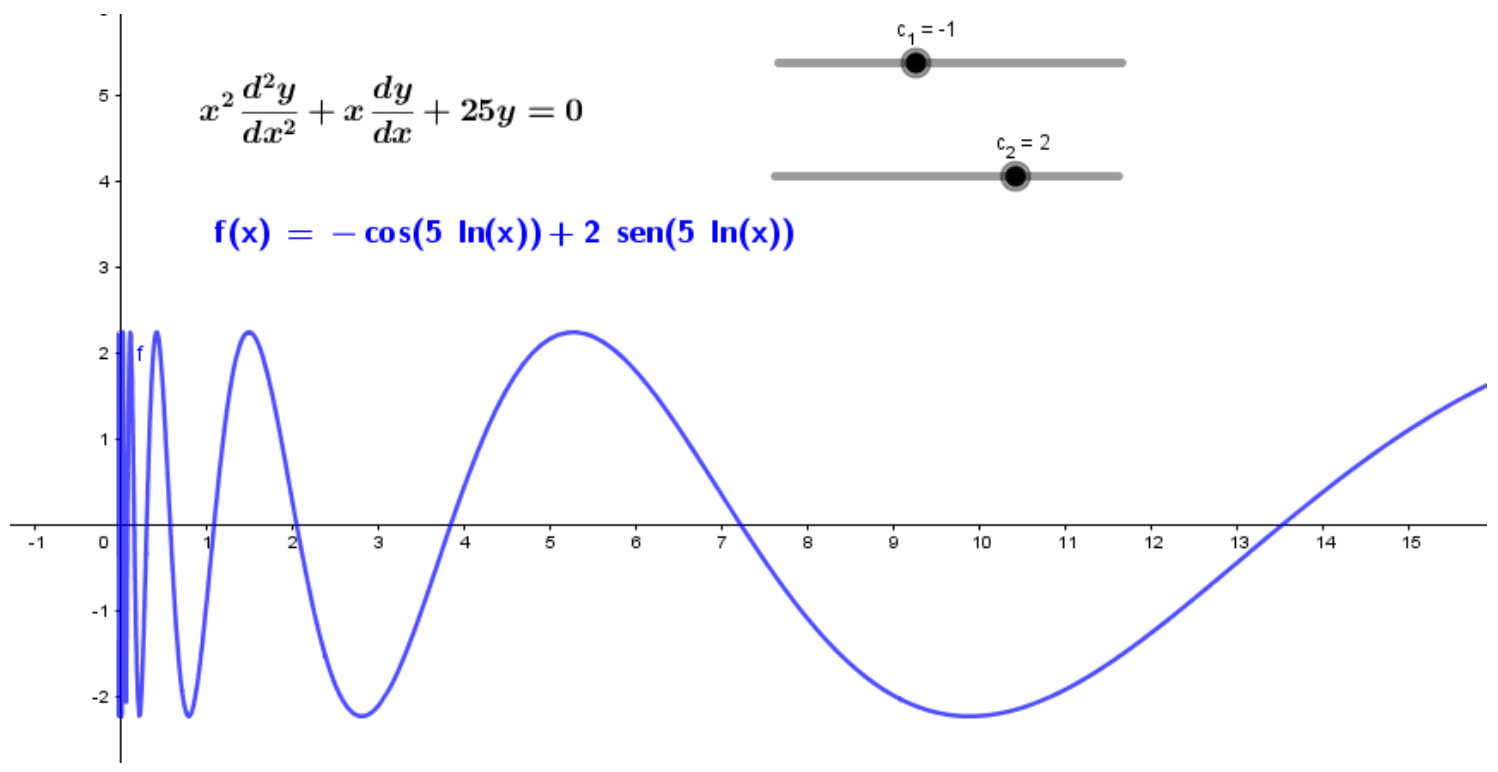

\section{Conclusion}

We see that GeoGebra applets can be a great teacher and student aid, since it allows us to accomplish the task of visualizing differential equations with their Cauchy-Euler solutions.

The purpose of this work has been to share and promote the use of GeoGebra in the different higher education mathematics courses as an aid in meaningful learning, especially in the ED, which are highly applicable in different areas of science and engineering.

\section{References}

[1] Dikovic, L (2009). Applications GeoGebra into teaching some topics of mathematics of mathematics at the college level. Computer Science and Information Systems, 6 (2).

[2] Ronnys JesúsVicent Millán, Fray Rafael de Dios Granados Pérez, Anner Luis Pariche Valdivieso (2019). "Propuesta para la enseñanza/aprendizaje de las coordenadas polares con GeoGebra”. XV CLAEM-LACME, Medellín, Colombia.

[3] National Council of teacher of mathematics. "De los principios a la acción. Para garantizar el éxito matemático para todos". México: Editando Libros 2015.

[4] Jorge Olivares, Elvis Valero (2019). Resolving non-homogeneous linear differential equations using the undetermined method coefficients and variation of parameters by means of GeoGebra. Journal of Physics Conference Series. 1391

[5] Jorge Olivares, Elvis Valero 2020, Linear homogenous linear differential equations of third and Conference on Research in Teaching and Education, ISBN: 978-609-485-0240 pub. Budapest, Hungary. 